\title{
Design Criteria for Privacy-Sensitive Healthcare Buildings
}

\author{
Chaham Alalouch, Peter A. Aspinall, and Harry Smith
}

\begin{abstract}
Architects are faced with many policies and guidance documents when designing hospitals. These differ in focus, structure and clarity. An Architect task of eliciting, understanding and responding to design criteria becomes even more confusing when it comes to intangible criteria such as patient's privacy. The aims of this paper is to identify and review main sources of information on hospital design that are available for architects in the UK in order to summarize these criteria and distill criteria related to privacy. The focus is on visual privacy as a function of the spatial arrangements of hospital wards which is, in turn, under the control of architects. The study employs a two-fold methodological approach: semi-structured interview with experts in hospital design; and content analysis and comparative investigation of policies and guidance documents. This exhaustive study revealed that the concern about privacy is clearly expressed in the surveyed documents. The privacy-related criteria are framed within the larger context of hospital and ward design criteria. This contributes to the existing scattered literature on hospital design criteria with a new summary of design criteria at three levels: ward spatial arrangements, patient's privacy, patient's visual privacy. The paper concludes with recommendations for future research on privacy-sensitive healthcare building design.
\end{abstract}

Index Terms-Design criteria, hospital, privacy, visual privacy, hospital ward, NHS.

\section{INTRODUCTION}

Designing a hospital has never been an easy task for architects. The design process of such a complex artifact requires architects to deal with a large number of design criteria. This includes not only dealing with the complex functional and clinical requirements within healthcare buildings but also other sensitive and less tangible consideration such as users psychological needs one of which is patient's privacy.

In addition to the widely acknowledged functional complexity of healthcare buildings, there are a large number of standard, guidance and requirements that need to be taken into consideration by architects during the design process of hospitals. The amount and focus of these varies from country to another.

In the UK for example the Department of Health and NHS Estates have published a vast number of guidance and standards documents to regulate and guide architects during the design process of healthcare buildings. These documents reflect the government policy with regards to healthcare delivery. In addition, recent research-based initiatives such as

Manuscript received July 21, 2014; revised September 23, 2014.

C. Alalouch is with Sultan Qaboos University, College of Engineering, CAE Dep., Muscat, Oman, BO.Bax33/123 (e-mail: c.alalouch@squ.edu.om).

P. A. Aspinall and H. Smith are with Heriot-Watt University, School of Built Environment, Edinburgh, EH14 4AS UK
Evidence-Based Design [1]-[3], and the global tendency to involve stakeholders in the design process of healthcare buildings has added more complexity to the design process of hospitals.

Although general hospitals can be divided into three functional areas - inpatient; diagnostic and treatment; and support -, the inpatient accommodation seems to attract public attention the most due to the fact that patients spend most of their hospital-style period in wards. Patients in wards are usually weak, and in a vulnerable state experiencing less control over their environment. This amplifies the influence of the ward design on their wellbeing and recovery time. Ulrich and colleagues showed that well designed architectural spaces have an impact on patients' recovery time, wellbeing and satisfaction [3]. In addition, wards occupy as much floor area as the other departments combined [4], [5].

Designing a hospital ward requires a special attention from the early stages of the design process to meet the wide range of issues which are involved in ward design. These include psychological needs of users which are less often considered but equally important such as patient privacy.

No doubt, privacy is a complex concept that is not easy to define [6], [7]. It is a multi-faceted construct which could be interpreted differently by different people. It is however understood within the context of this work in line with Sundstrom et al. [8] definition of architectural privacy who suggested, in page 2, that 'Architectural privacy refers to visual and acoustic isolation supplied by an environment'. The focus here is on visual privacy as a function of the spatial arrangements of spaces.

The rule of the designed physical environment -which is under the control of architects - in providing opportunities for privacy is widely recognized [9]-[11]. In particular, the interplay between individuals, social relationships and the physical environment has been seen as one facet of privacy [12]. According to the review by Leino-Kilpi et al. [13] most of the studies in the field of patients' privacy investigate physical privacy -i.e. visual and acoustics privacy- with emphasis on the hospital environment. Archea [10], [11] illustrated that spatial arrangements of the physical environment is crucially linked to the visual aspects of privacy. While acoustic privacy can be controlled by the technical specifications and engineering solutions, visual privacy seems to be more related to how architects design spaces within hospital wards. Despite this, it seems that there are a lack of studies that summarize design criteria which influence patient's privacy in hospital wards in order to make them more accessible for architects and healthcare authorities.

Patients' privacy in hospital settings is widely recognized as important for patients' well-being and satisfaction 
[14]-[21]. On a psychological level, the importance of privacy for system-maintenance and system-development has been acknowledged by both theory and research [22], [23]. Fulfilling people's needs for privacy is linked to their well-being [9], [24]. The evolution of recent trends and demands in the field of healthcare building design such as Patient-centered care [25] and Healing Environments [26] have further emphasized the concept of patients' privacy and its importance for patients' well-being. In the UK, a patient's privacy has been recognized as a key feature in designing the internal environment of hospitals [27], [2]. Improving patients' experience by providing a better level of privacy and dignity is one of the major schemes included in The NHS Plan 2000 which was reinforced later by the guidance and benchmarking document 'Essence of Care' [28]. In general, patients' privacy has been seen as a cornerstone for healthcare settings [29].

Adding these together results in a complex matrix of design criteria that need to be taken into consideration during the design process of healthcare building. Consequently, architects -as being a key player in the production of healthcare spaces- are left with scatter sources for design criteria that lacks clear classification and structure. These sources often include also engineering specifications, firs and safely guidelines, building services requirements and other information that is less relevant to the spatial arrangements of healthcare spaces, which is one of the main concerns for architects.

This makes the architects task in distilling, understanding, and responding to the relevant design criteria more challenging. When it comes to intangible design criteria such as patient's privacy, the task of architect become even more complex due to the difficulty associated with translating these criteria into design procedures. There is a need to simplify hospital ward design criteria and make them more accessible to practicing architects, particularly intangible requirements such as visual privacy which is the focus of this work.

This study aims to summarize design criteria at three levels -those that effect: ward spatial arrangement; patient's privacy; and patient's visual privacy- making them more accessible to architects. It aims also to assess how policies and guidance documents in the UK have dealt with architectural privacy in hospitals. In doing so, this study provides a unique sources for the minimum hospital ward design criteria that are related to patients privacy and in the same time are under the control of architects. It also provides a design aid to further enable architects and healthcare building providers to make better informed decision regarding design proposal of hospital wards.

\section{METHODS}

The research methodology adopts a dual approach consists of two sequential phases: Semi-structured interview with expert in healthcare building design from the UK followed by content analysis and cross-comparative investigation. The qualitative data collected in phase one provided the context for the more detailed study which investigates and summarizes design criteria that need be considered by architects during the design process of healthcare building in general and hospital word in particular.

The first phase is based on literature review and semi-structured interviews with experts from the UK. Participant's selection criteria, in addition to the practical experience in hospital ward design, involved: architects who contributed to the development of healthcare buildings regulations and guidelines documents in the UK; architects with experience in medical architectural research; and practicing architects from the healthcare design division in international architectural firms. The main aim of the interviews (among others) was to identify the information sources that are available to architects and designers with regards to hospital and ward design. The interviews aimed also to assess the extent to which the available information helps architects to design successful wards and assess interviewees' awareness of the relationship between the architectural design of wards and privacy of patients.

The second phase focused mainly on the content analysis and cross-comparison between the different information sources for hospital and ward design. This comparison allowed a systematic distillation of design criteria. Each design criterion was accompanied with brief explanatory text to avoid misunderstanding and possible differences in interpretation. The distilled design criteria were then systematically regrouped according to a certain filtering aspects that are of interest to the current study.

\section{RESULTS}

\section{A. Information Sources on Hospital Ward Design}

The exhaustive review of the literature -including policies and guidelines on hospital design in the UK- revealed an adequate awareness of the important of privacy for patients. Most of the Department of Health reports and guidelines which address issues related to the internal environment of hospitals emphasize the importance of achieving a better level of patients' privacy especially in wards. The role of the spatial arrangements is however less considered. In spite of this, there is no single document that summarizes information for architects on design criteria that are under their control and at the same time impact on the level of privacy in hospital wards.

The interviews revealed an adequate awareness among the interviewees of the importance of patients' privacy in hospital wards. All interviewees ranked patients' privacy as a very highly important criterion of ward design. However, participants acknowledged the difficulties associated with fulfilling patient' needs for visual and acoustics privacy through the spatial design of hospital wards. One of the main reason for this difficulties appear to be the unclear link in the available documents between how architectural design contributes to the achievement of the required level of patient's privacy.

On the other hand, there was a consensus among the interviewees that the documents managed by the Department of Health (DH) and published usually by The Stationery Office (TSO) forms the main sources of information by architects during the hospital design process and NHS trusts 
in preparing the briefing for hospital projects. Other sources include case studies from around the world and networking with people in the field. $\mathrm{DH}$ documents are categorized in the following series: Health Building Notes (HBNs); Heath Technical Memoranda (HTMs); Health Facility Notes (HFNs); Model Engineering Specifications (MES); Fire Practice Notes (FPNs); NHS Toolkits; and other NHS Estates and $\mathrm{DH}$ publications and reports which are published individually.

There is however a common belief that NHS Toolkits accumulates results of research and knowledge based on long experience and good understanding of health care design. The significance of these toolkits is that they incorporate both design-related criteria and the relevant evidence-based research in a non-technical way. As a consequence, most of design information sources which are related to healthcare building design seem to be covered in these toolkits in a relatively accessible way.

NHS Toolkits was developed to assist NHS Trusts in determining, managing and monitoring their requirements from the initial proposals through to post project evaluation. Nevertheless, these toolkits can be used by architects to self-evaluate their designs. These are: AEDET: Achieving Excellence Design Evaluation Toolkit; ASPECT: A Staff and Patient Environment Calibration Tool; IDEAs: Inspiring Design Excellence and Achievements and NEAT ${ }^{1}$ : NHS Environmental Assessment Tool. It was decided therefore to use these toolkits as bases for the current study.

\section{B. Establishing a Hierarchy of Design Criteria}

In order to filter these criteria, a taxonomy or hierarchical structure by which the distilled design criteria can be categorized needed to be defined. This was done in two stages:

Firstly, AEDET has a clear structure. This structure has been used to categorize all design criteria which were distilled from the four NHS toolkits for the following reasons: firstly, two toolkits (i.e. ASPECT and IDEAs) are mapped into the AEDET. Secondly, this structure was developed based on a well-establish evaluation tool namely Design Quality Indicators (DQI) [30].

The DQI has been developed to evaluate design quality of buildings in the four key stages of building development (i.e. the brief, mid-design, ready for occupation and in-use). In 2002, the Strategic Forum for Construction recommended using the DQI evaluation tool to judge the industry's ongoing performance in terms of building quality [31]. Since then DQI has been used widely in different types of projects. It became a well-known tool among architects in both the UK and USA [32]. More importantly, DQI structure is based on Vitruvius's qualities of architecture - i.e. firmitas, utilitas, venustas-, a language that every architect understands. Fig. 1 shows the structured used in this study.

Secondly, all elicited design criteria were filtered against five aspects according to the following definitions resulting in four groups of criteria:

1) Hospital architecture: this includes the criteria that may affect the architectural design of hospitals.

${ }^{1}$ NEAT has been replaced by BREEAM Healthcare since this project was conducted
2) Ward design: these are the criteria that related to different aspects of ward design (i.e. architectural design, interior design and engineering).

3) Ward spatial arrangements: a criterion was included under this category if it affects the spatial structure of the ward. This does not include physical aspects in wards such as color scheme, texture, lighting, etc.

4) Privacy: A criterion was listed under this category if it affected visual and/or acoustic privacy.

Visual Privacy: These are design criteria that may influence the visual privacy of patients.

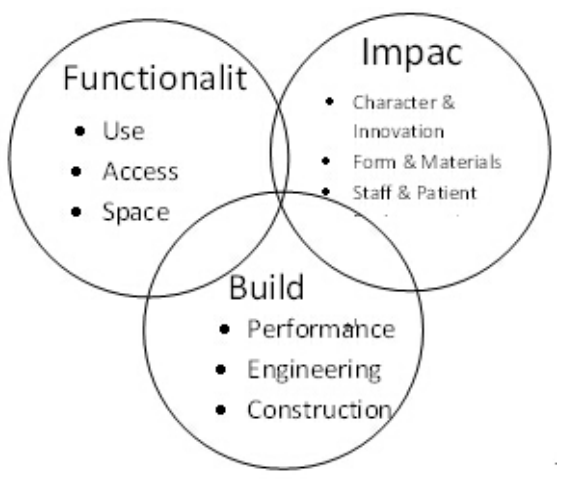

Fig. 1. AEDET Structure based on DQI.

\section{Design Criteria}

In total 128 exclusive criteria were elicited and reclassified using the structure explained in the previous section as shown in Fig. 2. Table I shows the distribution of the elicited design criteria among groups based on the sources of each criterion. The table shows a great deal of overlap between the toolkits. Over $36 \%$ of criteria were not exclusive to a single toolkit. Moreover, IDEAs did not contribute a single unique criterion to the overall set.

Based on the definition of the filtering aspects mentioned earlier, 70 criteria were found to be related to hospital architecture, 66 to ward design, 34 criteria are linked to ward spatial arrangements, 18 to privacy and 16 to visual privacy. Fig. 3 illustrates the percentage of criteria found to be related to each group.

Slightly less than the third of the criteria (39 criteria) were found not to be directly related to any of the groups that are of interest to this study. Further inspection showed that these criteria deal with issues such as landscape, transportation and site access, management systems, ecological considerations, pollution, waste management and alike.

Slightly more than half of the criteria $(54.7 \%)$ are found to be associated with the architectural design of hospitals. Only $14 \%$ of the criteria were associated with privacy, with marginally less criteria linked to visual privacy (only two criteria less). Fig. 4 shows a comparison between the four filtered groups of design criteria based on the percentage of their presence in each toolkits.

As shown in Fig. 5, ten criteria were found to have an impact on all groups. These criteria are: security \& supervision; standards; space segregation; company and dignity; gender segregation; toilets and bathrooms; views; facilities for patients; drinks facilities; and relative/friends stay. This suggests that these criteria need to be given great 
attention from the early stages of the design process due to their wide impact on the overall design. This is followed by five criteria that were found to have an impact on four groups out of the five. These criteria are: privacy in beds; private conversation; windows; acoustic design and noise.

TABLE I: DISTRIBUTION OF DESIGN CRITERIA

\begin{tabular}{|c|c|c|c|c|c|c|c|c|}
\hline \multicolumn{2}{|c|}{ Item of Comparison } & \multicolumn{2}{|c|}{ All Criteria } & \multicolumn{5}{|c|}{$\begin{array}{l}\begin{array}{l}\text { Filtered Criteria } \\
\text { (count) }\end{array} \\
\end{array}$} \\
\hline & & $\begin{array}{l}\text { Design Criteria } \\
\text { (count) }\end{array}$ & $\begin{array}{l}\text { Design Criteria } \\
(\%)\end{array}$ & Hospital Design & Ward Design & $\begin{array}{l}\text { Ward Spatial } \\
\text { Arrangements }\end{array}$ & Privacy & $\begin{array}{l}\text { Visual } \\
\text { Privacy }\end{array}$ \\
\hline \multirow{11}{*}{$\begin{array}{l}\text { NHS } \\
\text { Evalu } \\
\text { ation } \\
\text { Toolk } \\
\text { its }\end{array}$} & AEDET & 23 & 18 & 16 & 8 & 4 & $\frac{1}{1}$ & 1 \\
\hline & ASPECT & 24 & 19 & 16 & 19 & 10 & 4 & 4 \\
\hline & IDEAs & 0 & 0 & 0 & 0 & 0 & 0 & 0 \\
\hline & NEAT & 34 & 27 & 4 & 1 & 0 & 0 & 0 \\
\hline & AEDET+IDEAs & 17 & 13 & 17 & 14 & 0 & 0 & 2 \\
\hline & AEDET+NEAT & 2 & 1.6 & 2 & 0 & 7 & 2 & 0 \\
\hline & ASPECT+IDEAs & 15 & 12 & 5 & 12 & 7 & 6 & 5 \\
\hline & $\begin{array}{l}\text { AEDET+ASPECT } \\
+ \text { IDEAs }\end{array}$ & 6 & 4.7 & 5 & 6 & 3 & 3 & 3 \\
\hline & $\begin{array}{l}\text { AEDET+IDEAs+ } \\
\text { NEAT }\end{array}$ & 3 & 2.3 & 3 & 2 & 1 & 1 & 0 \\
\hline & $\begin{array}{l}\text { ASPECT+IDEAs+ } \\
\text { NEAT }\end{array}$ & 2 & 1.6 & 0 & 2 & 0 & 0 & 0 \\
\hline & $\begin{array}{l}\text { AEDET+ASPECT } \\
+ \text { IDEAs+NEAT }\end{array}$ & 2 & 1.6 & 2 & 2 & 2 & 1 & 1 \\
\hline \multicolumn{2}{|l|}{ Total } & 128 & 100 & 70 & 66 & 34 & 18 & 16 \\
\hline
\end{tabular}

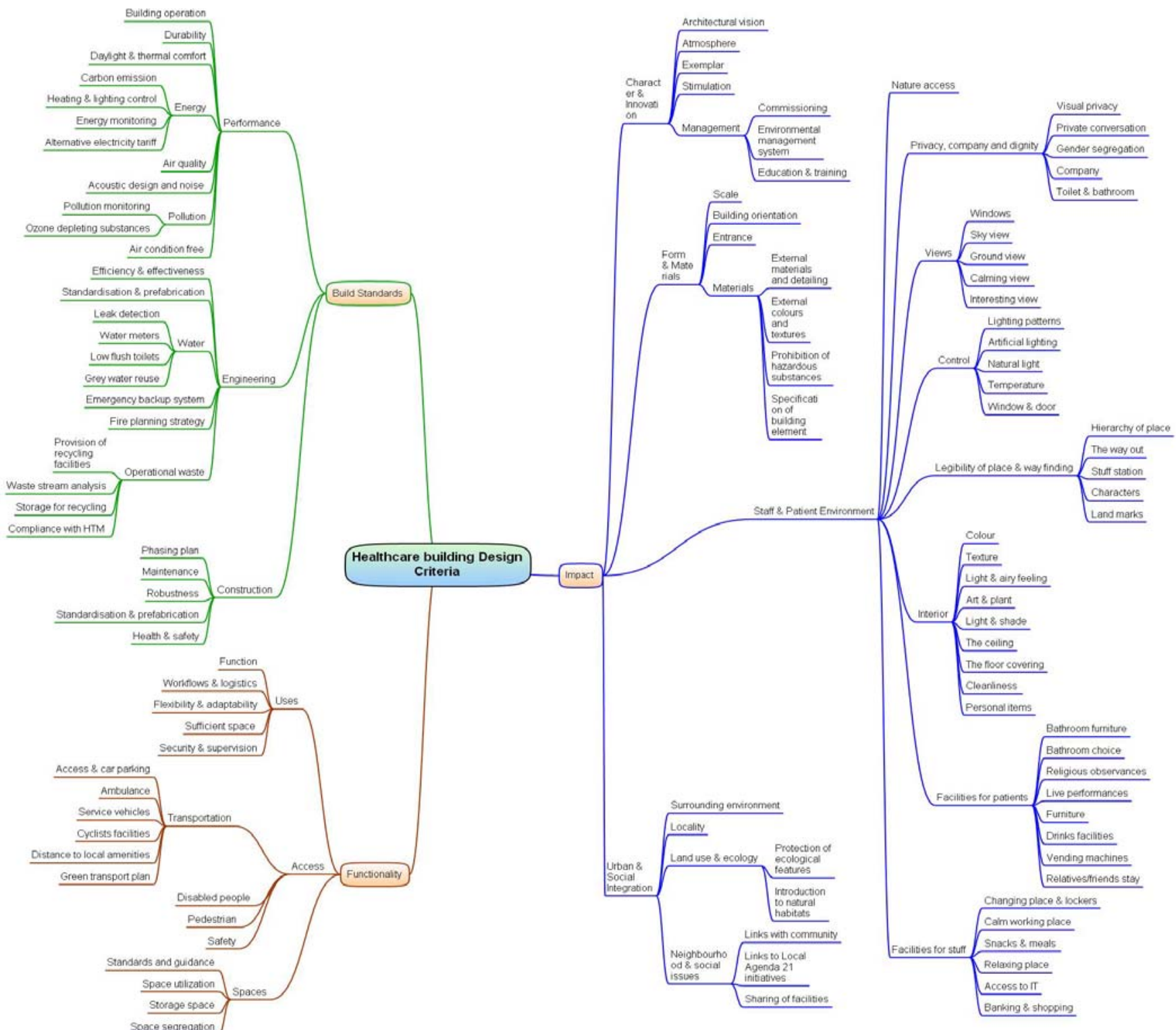

Fig. 2. Hospital design criteria. 


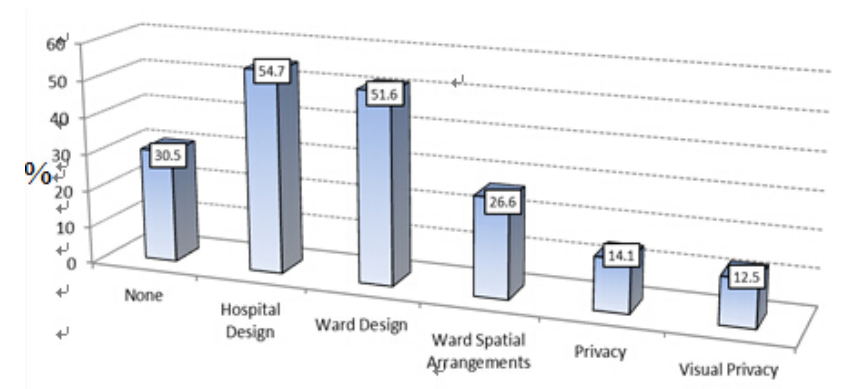

Fig. 3. Percentage of criteria in each group.

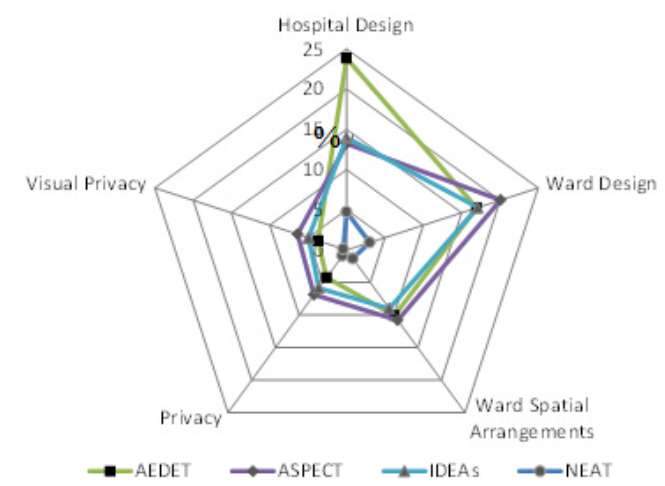

Fig. 4. Comparison between the five groups of design criteria.

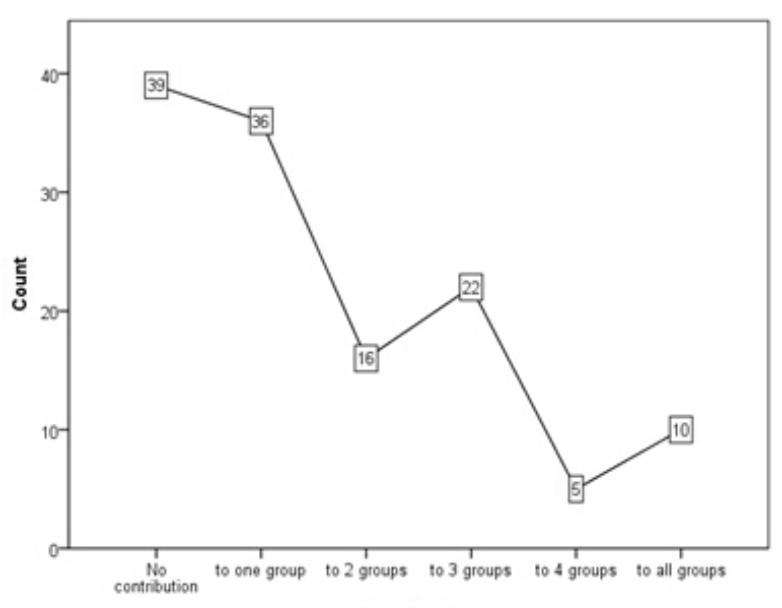

Contribuation

Fig. 5. Contribution of design criteria to group (total=128, Std. Deviation=1.544).

\section{Ward Spatial Arrangements, Privacy, and Visual Privacy}

We constructed a similarity matrix to identify criteria that were found to contribute to each pair of the groups. In this matrix, which is shown in Table II, cells represent the number of shared design criteria between each pair of groups.

\begin{tabular}{l|c|c|c|c|c|}
\multicolumn{7}{|c|}{ TABLE II: NUMBER OF SHARED CRITERIA BETWEEN PAIRS OF GROUPS } \\
& Hospital Design & Ward Design & $\begin{array}{c}\text { Ward Spatial } \\
\text { Arrangements }\end{array}$ & Privacy & Visual Privacy \\
\hline Hospital Design & 70 & & & & \\
\hline Ward Design & 47 & 66 & & & \\
\hline $\begin{array}{l}\text { Ward Spatial } \\
\text { Arrangements }\end{array}$ & 31 & 34 & 34 & & \\
\hline Privacy & 13 & 18 & 14 & 18 & \\
\hline Visual Privacy & 11 & 16 & 12 & 16 & 16 \\
\hline
\end{tabular}

TABLE III: WARD SPATIAL ARRANGEMENTS, PRIVACY AND VISUAL PRIVACY

\begin{tabular}{|c|c|c|c|c|c|c|}
\hline \multicolumn{3}{|c|}{ Ward Design Criteria } & Consideration & $\begin{array}{l}\text { Ward spatial } \\
\text { arrangements }\end{array}$ & Privacy & $\begin{array}{l}\text { Visual } \\
\text { privacy }\end{array}$ \\
\hline \multirow{16}{*}{ Functionality } & \multirow{5}{*}{ Use } & Function & The functional requirements and the relationships & $\bullet$ & & \\
\hline & & $\begin{array}{l}\text { Workflows \& } \\
\text { logistics }\end{array}$ & $\begin{array}{l}\text { The optimal arrangements of the workflows and } \\
\text { logistics }\end{array}$ & $\bullet$ & & \\
\hline & & $\begin{array}{l}\text { Flexibility \& } \\
\text { adaptability }\end{array}$ & $\begin{array}{l}\text { The flexibility for the change and expansion and } \\
\text { the adaptability in use }\end{array}$ & $\bullet$ & & \\
\hline & & Sufficient space & $\begin{array}{l}\text { Sufficient spaces for the different activities and } \\
\text { the workloads }\end{array}$ & $\bullet$ & & \\
\hline & & $\begin{array}{l}\text { Security \& } \\
\text { supervision }\end{array}$ & $\begin{array}{l}\text { The facilitation of control, security and } \\
\text { supervision }\end{array}$ & $\bullet$ & • & $\bullet$ \\
\hline & \multirow{4}{*}{ Space } & $\begin{array}{l}\text { Standards and } \\
\text { guidance }\end{array}$ & $\begin{array}{l}\text { The use of appropriate space standards and } \\
\text { guidance }\end{array}$ & $\bullet$ & • & $\bullet$ \\
\hline & & Space utilization & Acceptable ratio of usable space to the total area & $\bullet$ & & \\
\hline & & Storage space & The provision of adequate storage spaces & $\bullet$ & & \\
\hline & & Space segregation & $\begin{array}{l}\text { Achieving segregation between spaces when } \\
\text { necessary }\end{array}$ & $\bullet$ & $\bullet$ & $\bullet$ \\
\hline & \multirow{7}{*}{$\begin{array}{l}\text { Staff \& Patient } \\
\text { Environment }\end{array}$} & Access to nature & $\begin{array}{l}\text { Patients' access to nature outside and inside the } \\
\text { building }\end{array}$ & $\bullet$ & & \\
\hline & & $\begin{array}{l}\text { Company and } \\
\text { dignity }\end{array}$ & $\begin{array}{l}\text { The ability of patients to maintain their privacy } \\
\text { and their interaction with others }\end{array}$ & $\bullet$ & $\bullet$ & $\bullet$ \\
\hline & & Visual privacy & $\begin{array}{l}\text { Patients can chose to have visual privacy in bed } \\
\text { area and changing area }\end{array}$ & $\bullet$ & $\bullet$ & $\bullet$ \\
\hline & & $\begin{array}{l}\text { Private } \\
\text { conversation }\end{array}$ & Patients can have private conversation & $\bullet$ & $\bullet$ & \\
\hline & & $\begin{array}{l}\text { Gender } \\
\text { segregation }\end{array}$ & $\begin{array}{l}\text { Gender segregation principles are reflected in the } \\
\text { design }\end{array}$ & $\bullet$ & $\bullet$ & $\bullet$ \\
\hline & & Company & Patients have places where they can be with others & $\bullet$ & $\bullet$ & \\
\hline & & Toilet \& & Toilet \& bathroom are located logically, & $\bullet$ & $\bullet$ & $\bullet$ \\
\hline
\end{tabular}




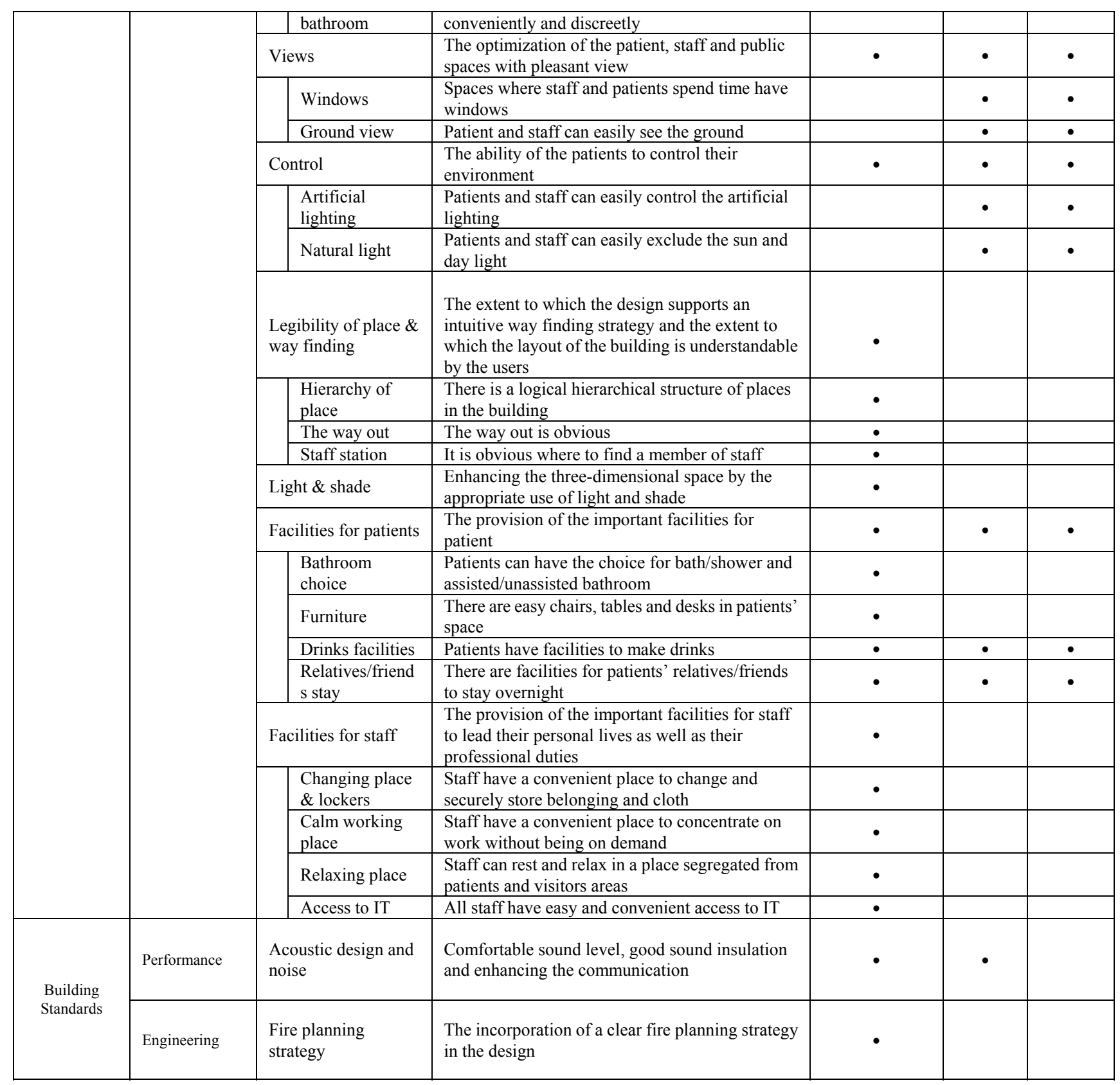

The analyses in Table II confirms that designing a hospital ward requires architects to deal with not only criteria related to the architectural design of the whole hospital but it also necessitates the consideration of ward-specific design criteria $(66-47=19$ exclusive ward design criteria). Out of the 34 ward spatial arrangements criteria, 14 criteria were found in the privacy group and 12 criteria in the visual privacy group. Unexpectedly, all of the 16 visual privacy criteria were found in the privacy group. Table III summarizes design criteria which are found to have an impact on ward spatial arrangements, privacy and visual privacy.

Further inspection revealed that the reviewed documents dealt with patient's visual privacy from the perspective of space segregation, windows and view, movement in wards and control over the environment. None of the documents approached visual privacy ,and privacy, from a patient's perspective. And also visual privacy was not approached from the perspective of privacy as a function of the spatial configuration as the literature suggests. Moreover, acoustic privacy was dealt with from the perspective of providing opportunity for private conversation and not as a function of spatial configuration as a whole.

\section{Discussion AND CONCLUSIONS}

In this work, the aims was to elicit, filter and re-structure the scattered design criteria from regulations, policies and guidelines documents that are related to healthcare building design at three levels (ward spatial arrangement, privacy and visual privacy), eliminating repetition and making them more accessible to architects and healthcare authorities. The focus is on patient's privacy as one of the basic human needs for which patients have legal rights [17], [20]; and on visual privacy as a design criterion that is highly influenced by the architectural design of hospital wards.

The findings illustrate the complexity facing architects during the design process of hospitals in general and wards in particular. This is partially due to the large number of documents that are relevant to healthcare building design, and to the scattered design criteria within these documents 
without a clear instruction to guide architects on how these criteria could be practically met.

In total 128 design criteria were elicited. These are the minimum design criteria that architects need to be aware of during the hospital design process. The resulted list of design criteria, if companied with clear definition and explanation, could form the bases for an exhaustive quality indicator for healthcare buildings. This can be used by architects to guide their designs and by healthcare authorities for briefing and appraisal of proposals.

On the other hand, the resulted list allowed the identification of design criteria that are related to privacy and visual privacy. In other words, those design criteria that are under the control of architects and which at the same time may increase or decrease patients' privacy.

This exhaustive study revealed that the concern about privacy is clearly expressed in the surveyed documents. However and in spite of the wide recognition of the importance of patient's privacy in hospital wards by experts in the healthcare building design and the well-established link in the literature between the architectural design and the level of privacy offered by an architecturally bounded environment, it seems that policies and guidance available for architects in the UK still underestimate the relationship between these two issues. Patient visual privacy as a function of the architectural design of wards still, in spite of its importance, understudied.

The literature mostly focuses on emphasising the importance of the provision of adequate level of privacy but does not clarify the role of the spatial arrangement in fulfilling this requirement. In particular, the impact of ward spatial arrangements on the level of visual privacy offered in a ward need to be further considered. Additionally, patient's preferences for privacy seems to be neglected by the surveyed documents. In a previous study Alalouch et al. [33], [34] found that two quantitative measures of the spatial configuration of generic hospital wards -i.e. integration and control- are associated with people preferences for locational privacy. These two measures are originated in space-syntax theory and represent how spaces are connected to each other and to the global spatial structure of a building which is under the control of architects.

The limitation of this study lies in the availability and selection of the analyzed materials. No claim is made about the comprehensiveness of the analyzed documents as the selection of documents was informed by the interviews with experts on healthcare building design and consequently was limited to a relatively small, but representative, set of sources i.e. NHS design evaluation toolkits. Another limitation is that this study is purely empirical and did not explore how architects prioritize design criteria during the design process of hospitals. An earlier study has used relatively new statistical technique, namely choice-based conjoint analysis, to investigate how architects prioritize 10 ward design criteria that were viewed as the most important by design experts [35].

Furthermore, the independency of design criteria was not part of this work. Interaction effects between some criteria is likely. However, this is out of the scope of the current study and is a subject of future research. Future research should focus also on providing practical suggestions and best practice examples in order to demonstrate the impact of different spatial arrangements of hospital wards on patient's privacy.

The development of evaluation and control methods for patients' privacy in healthcare building is greatly needed to help architects to assess the required level of privacy and compare it to what their design proposals are likely to offer. This is, both to evaluate and control the development of design proposals and to analyze existing facilities, resulting in improving patient's satisfaction and wellbeing as well as the overall quality of healthcare buildings. One significant feature of this paper is that the privacy-related results are framed within the larger framework of hospital and ward design criteria, contributing to the existing scattered literature on hospital design criteria with a new summary of design criteria at three levels: ward spatial arrangements, patient's privacy, patient's visual privacy.

\section{REFERENCES}

[1] R. Ulrich, Effects of Healthcare Environmental Design on Medical Outcomes, Design and Health World Congress and Exhibition (WCDH), USA: The International Academy for Design and Health (IADH), 2000.

[2] NHS Estates, Exploring the patient environment - An NHS Estates Workshop, UK: TSO, 2003.

[3] R. Ulrich, X. Quan, C. Zimring, A. Joseph, and R. Choudhary. The Role of the Physical Environment in the Hospital of the 21st Century: A Once-in-a-Lifetime Opportunity. [Online]. Available: http://www.healthdesign.org/research/reports/physical_environ.php.

[4] A. Cox and P. Groves, Hospitals and Health-Care Facilities : A Design and Development Guide, London: Butterworth Architecture, 1990.

[5] R. Glanville and A. Howard, "Hospitals," in Metric Handbook-Planning and Design Data, 2nd ed., D. Adler.Eds. Great Britain: Architectural Press, 1990.

[6] P. B. Newell, "Perspectives on privacy," Journal of Environmental psychology, vol. 15, pp. 87-104, 1995.

[7] D. J. Solove, “A taxonomy of privacy," University of Pennsylvania Law Review, vol. 154, no. 3, pp. 477, 2006.

[8] E. Sundstrom, B. Robert, and K. Douglas, "Privacy at work: Architectural Correlates of job satisfaction and job performance," The Academy of Management Journal, vol. 23, no. 1, pp. 101-117, 1980.

[9] I. Altman, The Environment and Social Behaviour: Privacy, Personal space, Territory, Crowding, Monterey, CA: Cole Publishing Company, 1975.

[10] J. Archea, "The place of architectural factors in behavioral theories of privacy," Journal of Social Issues, vol. 33, pp. 116-137, 1977.

[11] J. Archea, 'Visual access and exposure: An architectural basis for interpersonal behavior," Ph.D. dissertation, Pennsylvania State University, 1984.

[12] I. Altman, "Toward a transactional perspective: A personal journey," in Environment and Behavior Studies: Emergence of Intellectual Traditions, New York: Plenum Press, 1990, pp. 225-255.

[13] H. L. Kilpi et al., "Privacy: a review of the literature," International Journal of Nursing Studies, vol. 38, pp. 663-671. 2001.

[14] WMA, Word Medical Association Declaration of Helsinki - Ethical Principles for Medical Research Involving Human Subjects, Helsinki: Word Medical Association, 1994.

[15] G. Annas, "Invasion of privacy in the hospital," Nurse Law Ethics, vol. 2, no.1, pp. 3, 1981.

[16] I. Thompson, K.Melia, and K. Boyd, Nursing Ethics, Singapore: Churchill Livingstone, 1994.

[17] WHO, A declaration on the Promotion of Patients' Rights in Europe, Amsterdam: World Health Organisation Regional office for Europe, $28^{\text {th }}$ June 1994.

[18] NHS Estates, HBN4(1) - Inpatient Accommodation Options for Choice, London: HMSO, 1997.

[19] E. Back and K. Wikblad, "Privacy in hospital," Journal of Advanced Nursing, vol. 27, no.5, pp. $940-945,1998$.

[20] J. Woogara, "Human rights and patients' privacy in UK hospitals," Nursing Ethics, vol. 8, no. 3, pp. 234- 246, 2001. 
[21] R. M. Matiti and G. Trorey, "Perceptual adjustment levels: patients' perception of their dignity in the hospital setting." International Journal of Nursing Studies, vol. 41, pp. 73 -744, 2004.

[22] P. B. Newell, "A systems model of privacy" Journal of Environmental psychology, vol. 14, pp. 65-78, 1994.

[23] P. B. Newell, "A cross-cultural comparison of privacy definitions and functions: a system approach," Journal of Environmental psychology, vol. 18, pp. 357-371, 1998.

[24] E. K. Hoekstra and H. M. J. A. Liempd, "Pruimte voor patienten. Bouwen aan ziekenhuizen vanuit patientenperspectierf," The Netherlands: STAGG, 2001.

[25] N. Mead and P. Bower, "Patient-centred consultations and outcomes in primary care: a review of the literature," Patient Education and Counselling, vol. 48, no. 1, pp. 51-61, 2002.

[26] A. E. V. d. Berg, "Health impacts of healing environments: a review of evidence for benefits of nature, daylight, fresh air, and quiet in healthcare settings," Groningen: University Hospital Groningen, 2005.

[27] Department of Health, HBN 04-01: Adult in-Patient Facilities, London: The Stationery Office, 2008.

[28] Department of Health, The Essence of Care: Patient-focused Benchmarks for Clinical Governance, London: The Stationery Office, 2003.

[29] S. Glen and S. Jownally, "Privacy: a key nursing concept," British Journal of Nursing, vol. 4, no. 2, pp. 69-72, 1995.

[30] D. M. Gann, A. J. Salter, and J. K. Whyte, "Design quality indicator as a tool for thinking," Building Research \& Information, vol. 31, no. 5, pp. 318-333, 2003.

[31] The Strategic Forum for Construction, Accelerating Change, London: Rethinking Construction, 2002.

[32] D. Zemke and M. Pullman, "Assessing the value of good design in hotels," Building Research and Information, vol. 36, no. 6, pp.543-556, 2008.

[33] C. Alalouch and P. Aspinall, "Spatial attributes of hospital multi-bed wards and preferences for privacy," Facilities, vol. 28, no. 9/1, pp. 345-362, 2007.

[34] C. Alalouch, P. Aspinall, and H. Smith, "On locational preferences for privacy in hospital wards," Facilities, vol. 27, no.3/7, pp. 88-106, 2009.

[35] C. Alalouch, P. Aspinall, and H. Smith, "Architects' priorities for hospital ward design criteria: application of choice-based conjoint analysis in architectural research," Journal of Architectural and Planning Research, vol. 10, no. 11, 2011.

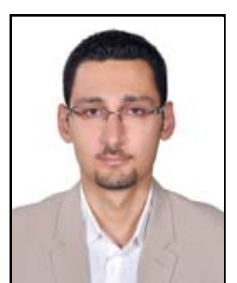

C. Alalouch received his bachelor degree in architectural engineering in 2002 and PG diploma in architectural design in 2004 from University of Aleppo, Syria. He was awarded his $\mathrm{PhD}$ in architecture from the School of the Built Environment, Heriot-Watt University, Edinburgh, UK in 2009.

He worked as a research associate at School of the Built Environment, Heriot-Watt University, Edinburgh, UK, from 2008 till 2010. In 2011 he started working as a lecturer in Itihad Private University (IPU) in Syria. He is currently working as an assistant professor in architectural engineering at Dep. of Civil and Architectural Engineering, College of Engineering, Sultan Qaboos University, Oman (since 2013). His research interest includes the relationship between the built environment and people perception, sustainable behavior, and quality of life. Previous research included the development of a tool for benefit quantification for healthcare infrastructure projects.

Dr. Alalouch is an architect with practical experience in Syria and the UK.

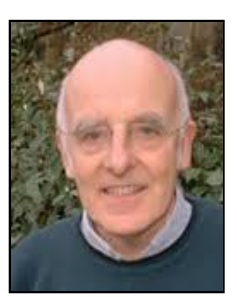

P. A. Aspinall has an MSc in psychology and a $\mathrm{PhD}$ in ophthalmology from The University of Edinburgh and has held an honorary fellowship in ophthalmology for over 30 years.

He worked as a research associate in psychology, Edinburgh University (1965-1968), research fellow in ophthalmology, Edinburgh University (1969-1974), honorary fellow in School of Clinical Sciences Edinburgh University since 1975, lecturer/senior lecturer in architecture Edinburgh College of Art (1974-1989), research director in landscape Architecture and Environmental Studies (1990-1996), research in director and professor in Edinburgh College of Art (1996-1999), professor in School of Built Environment Heriot-Watt University (2000-2005), Emeritus Professor Heriot-Watt University (2006), Co-Director of Vision Centre3 and Associate Director of OPENs pace. The central themes of his research have been aspects of visual function and quality of life, environmental psychology and inclusive design.

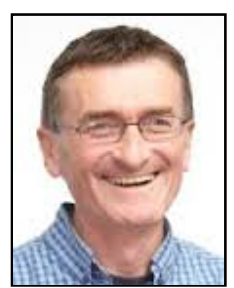

H. Smith was trained as an architect at the Universidad Politecnica de Valencia (1990), Spain, where he worked in private practice. MSc in urban \& regional planning (developing countries) in 1996, followed by a $\mathrm{PhD}$ in Planning and Housing focused on low-income housing in Costa Rica in 2000, both at Edinburgh College of Art/Heriot-Watt University.

He worked in the private sector as an architect and a planner in Edinburgh between 1996 and 2000, central development officer at Community Self-Build Scotland, Glasgow, 2000/01. Researcher at the School of Planning \& Housing, Edinburgh College of Art (1999/2000 and 2001/02), and then at the School of the Built Environment, Heriot-Watt University (2002/04). Since 2004, a lecturer at the School of the Built Environment, becoming a senior lecturer in 2010. His research interests include human settlements in the rapidly urbanizing world, community empowerment, participatory processes, and urban place-making and place-keeping 